\title{
Detection and Characterization of Benzimidazole Resistance in California Populations of Colletotrichum cereale
}

\author{
Francis P. Wong, Karla A. de la Cerda, Rufina Hernandez-Martinez, and Sharon L. Midland, Department of \\ Plant Pathology and Microbiology, University of California, Riverside 92521
}

\begin{abstract}
Wong, F. P., de la Cerda, K. A., Hernandez-Martinez, R., and Midland, S. L. 2008. Detection and characterization of benzimidazole resistance in California populations of Colletotrichum cereale. Plant Dis. 92:239-246.

Colletotrichum cereale is the causal agent of turfgrass anthracnose, which has become a serious problem on annual bluegrass (Роа аппиа) and creeping bentgrass (Agrostis palustris) golf course putting greens. Thiophanate-methyl is a benzimidazole (methyl benzimidazole carbamate [MBC]) fungicide used for the management of anthracnose. In this study, we examined 481 isolates from 10 California populations to determine the presence and frequency of MBC resistance. An in vitro methodology was developed to construct a baseline sensitivity distribution using 60 isolates from an unexposed population (TCGC). The $50 \%$ effective dose $\left(\mathrm{ED}_{50}\right)$ values for the baseline sensitivity distribution for thiophanate-methyl ranged from 0.14 to $2.3 \mu \mathrm{g} / \mathrm{ml}$ with a mean of $0.75 \mu \mathrm{g} / \mathrm{ml}$. For 60 isolates assayed from an exposed population (AHCC), 57 isolates were not responsive to in vitro concentrations of thiophanate-methyl of up to $30 \mu \mathrm{g} / \mathrm{ml}$. Isolates nonresponsive to thiophanate-methyl were not responsive to benomyl in vitro. Two isolates nonresponsive in vitro to thiophanate-methyl or benomyl were not controlled in vivo on annual bluegrass plants treated preventively with either fungicide at $11 \mathrm{mg} / \mathrm{ml}$, confirming the results of the in vitro testing. The remaining 361 isolates from eight populations were tested using the single discriminatory dose of thiophanate-methyl at $10 \mu \mathrm{g} / \mathrm{ml}$. A high proportion $(>90 \%)$ of isolates from six of the populations were resistant to thiophanate-methyl, indicating the presence of practical resistance at these locations. To determine the molecular mechanism of MBC resistance, the two $\beta$-tubulin genes, TUB1 and TUB2, of 12 resistant and 6 sensitive isolates were amplified and sequenced, revealing a glutamic acid to lysine substitution at position 198 of TUB2 that was present in all resistant isolates. This work confirms the presence of MBC resistance in $C$. cereale populations from California and presents methods and information that can be used to manage resistance to the MBC fungicides and improve anthracnose management programs.
\end{abstract}

Turfgrass anthracnose, caused by Colletotrichum cereale (4), is a re-emergent disease of annual bluegrass (Poa annua L.) and creeping bentgrass (Agrostis palustris L.) golf course putting greens. Although originally considered a disease of stressed cool-season turf $(12,25)$, it recently has become a difficult disease to manage (4). Outbreaks in California golf courses from 1999 through 2001 were extremely hard to control with standard fungicide programs (L. Stowell, personal communication). Fungicide resistance was suspected as part of the reason why the disease has been more difficult to control, and studies were undertaken to determine the presence and severity of resistance to single-site modeof-action fungicides. Recent work had shown that the development of fungicide resistance to the QoI and demethylation

Corresponding author: F. P. Wong

E-mail: frank.wong@ucr.edu

Accepted for publication 10 September 2007.

doi:10.1094/PDIS-92-2-0239

(C) 2008 The American Phytopathological Society inhibitor (DMI) fungicides in California populations of $C$. cereale contributed to the difficulties in managing the disease (33-35). The objective of the work presented here was to examine resistance development to the benzimidazole fungicides which historically have been used for the control of anthracnose on golf course putting greens and continue to be used as part of chemical control programs.

The benzimidazole or methyl benzimidazole carbamate (MBC) fungicides all act by inhibition of nuclear division via inhibition of microtubule assembly during mitosis by binding to $\beta$-tubulin subunits (14). Thiophanate-methyl currently is registered in the United States for the control of anthracnose and other diseases of turfgrass. Benomyl, another MBC fungicide, was registered previously but has been discontinued for use on turfgrass since 2001. Resistance to MBC fungicides is conferred by a single nucleotide change in the $\beta$ tubulin gene (16) and the risk of resistance development generally is considered to be high. Resistance to MBC fungicides was reported in cucurbit powdery mildew (Sphaerotheca fuliginea) soon after their introduction (24) and, to date, MBC resis- tance has been reported in over 90 different plant pathogens (8). Specifically for turfgrass pathogens, it has been documented for dollar spot (Sclerotinia homoeocarpa) (3), pink snow mold (Microdochium nivale) (11), and anthracnose in 1989 (7).

Given the length of time that MBC fungicides have been used for anthracnose control and the documentation of MBC resistance in C. cereale as early as 1989 , it was possible that $\mathrm{MBC}$ resistance was present in California populations of $C$. cereale. Thus, the objective of this study was to determine the presence and extent of MBC resistance in California populations of $C$. cereale. Specifically, the goals of this investigation were to (i) determine the baseline sensitivity of $C$. cereale to thiophanate-methyl, (ii) confirm cross resistance among isolates to both thiophanate-methyl and benomyl, (iii) conduct a survey for California populations of $C$. cereale at locations where $\mathrm{MBC}$ resistance was suspected, and (iv) determine the molecular mechanism for MBC resistance in California isolates of $C$. cereale. The information gathered from this work would contribute to the management of the disease by determining the potential presence and frequency of MBC resistance in California populations of the pathogen and allow for the modification of fungicide control programs as needed.

\section{MATERIALS AND METHODS}

Isolate collection. Monoconidial isolates were collected from annual bluegrass from 10 California locations as previously described (34). Two unexposed, or "baseline," populations were collected from fairways not sprayed by fungicides, and eight exposed populations from locations that had reported poor control of the disease with their fungicide programs on putting greens (Table 1). For the eight exposed locations, MBC fungicides were used approximately one to five times per year on putting greens for approximately 10 years as part of the anthracnose management programs. Three to eight samples were collected from diseased areas on a green from each location with a $11-\mathrm{cm}-$ diameter cup cutter, with samples taken at least $1 \mathrm{~m}$ apart from each other in an attempt to obtain a diverse sample. At the baseline locations, fungicides had not been applied to fairways from which the isolates were collected. Fairway samples were 
obtained by using a zigzag sampling strategy on each approximately $12,000-\mathrm{m}^{2}$ fairway area, taking plugs at least $10 \mathrm{~m}$ apart from each other to obtain a diverse sample. Although there was a risk for some movement of fungicide-exposed isolates onto fairways, the use of different equipment for mowing and cultivating putting greens and fairways and sampling away from putting greens minimized the chances of sampling these isolates. For the sake of this study, samples from fairways were considered unexposed, baseline isolates.

Isolates were obtained from samples by taking 12 infected plants from each plug, placing each infected plant in $300 \mu \mathrm{l}$ of sterile distilled water $\left(\mathrm{sdH}_{2} \mathrm{O}\right)$, streaking the spore suspension on $2 \%$ acidified water agar, and selecting single germinating conidia with a pin as described by Wong et al. (35). Isolates were maintained at $28^{\circ} \mathrm{C}$ on quarter-strength potato dextrose agar (1/4-PDA: $19.5 \mathrm{~g}$ of PDA and $11.3 \mathrm{~g}$ of granulated agar per liter of deionized water) in $100-\mathrm{mm}$-diameter petri plates, with transfers to new media made approximately every 14 days. Unless otherwise noted, all supplies were purchased from Fisher Scientific (Pittsburg, PA)

Fungicides. Technical grade thiophanate-methyl (93\% active ingredient [a.i.]; BASF Ag Products, Research Triangle Park, NC) was used for in vitro assays, whereas a formulated product, Cleary's 3336 50WP (50\% a.i.; Cleary Chemical Corporation, Dayton, NJ) was used for in vivo assays. Technical grade benomyl was not available; thus, the formulated product, Benlate 50WP (50\% a.i.; E.I. du Pont de Nemours and Company, Wilmington, DE) was used for both in vitro and in vivo assays.

In vitro fungicide assays. The unexposed population TCGC (60 isolates) was used to construct the initial baseline sensitivity distribution. An exposed population, AHCC (60 isolates), was used for comparison. The in vitro methodology was similar to that used previously (34). Briefly, thiophanate-methyl was dissolved and diluted in acetone to obtain stock solu- tions with concentrations of $5,15,50,150$, $500,1,500,5,000$, and $15,000 \mu \mathrm{g} / \mathrm{ml}$. All stock solutions were stored at $-20^{\circ} \mathrm{C}$ in 15 $\mathrm{ml}$ polystyrene centrifuge tubes sealed with Parafilm. One milliliter of each stock solution or acetone only was added to 500 $\mathrm{ml}$ of $1 / 4-\mathrm{PDA}$ (previously autoclaved and cooled to $40^{\circ} \mathrm{C}$ ) to obtain media containing thiophanate-methyl at $0,0.010,0.030$, $0.10,0.30,1.0,10$, and $30 \mu \mathrm{g} / \mathrm{ml}$. Media were poured into 100 -mm-diameter petri plates, using approximately $20 \mathrm{ml}$ per plate, and allowed to solidify for $24 \mathrm{~h}$. Fresh batches of media were prepared immediately prior to use in sensitivity assays. For testing, a 5-mm-diameter plug from a 7-day-old culture of an isolate of $C$. cereale was placed on the center of a plate of media amended with one of the nine fungicide concentrations. Plates were incubated at $28^{\circ} \mathrm{C}$ without light and colony diameters were measured 7 days later. The $50 \%$ effective dose $\left(\mathrm{ED}_{50}\right)$ values were determined by plotting the percent relative growth (RG) on each fungicide-amended medium compared with growth on the nonamended check versus the log concentration of the fungicide treatment, and then calculating the regression line through the linear portion of the dose-response curve as described previously by Wong et al. $(35,36)$. The assay was performed once for each isolate. $\log \mathrm{ED}_{50}$ data was used to construct histograms for populations TCGC and AHCC, and mean values were compared using $t$ tests (SAS v. 9.0; SAS Institute, Cary, NC).

To demonstrate cross resistance to benomyl, 25 isolates were selected randomly from the exposed population AHCC and the unexposed population TCGC and $\mathrm{ED}_{50}$ values were determined as described above, except that Benlate 50WP (50\% benomyl) dispersed in $\mathrm{sdH}_{2} \mathrm{O}$ was substituted for thiophanate-methyl. The concentrations of benomyl in the media were the same as those used for thiophanate-methyl (e.g. $0,0.010,0.030,0.10,0.30,1.0,10$, and $30 \mu \mathrm{g} / \mathrm{ml}$ a.i.).

Evaluation of $C$. cereale populations for sensitivity to thiophanate-methyl.

Table 1. Origin and number of Colletotrichum cereale isolates collected in 2002 to 2004 for fungicide sensitivity testing

\begin{tabular}{|c|c|c|c|c|c|}
\hline $\begin{array}{l}\text { Population } \\
\text { code }\end{array}$ & Location & Origin $^{a}$ & $\begin{array}{c}\text { Exposed to } \\
\text { benzimidazoles }^{\text {b }}\end{array}$ & $\begin{array}{c}\text { No. of } \\
\text { isolates }\end{array}$ & $\begin{array}{c}\text { Collection } \\
\text { date }\end{array}$ \\
\hline AHCC & San Bernardino, CA & Putting green & Yes & 60 & 2002 \\
\hline ANGC & Pasadena, CA & Putting green & Yes & 28 & 2002 \\
\hline $\mathrm{BHCC}$ & Danville, CA & Putting green & Yes & 21 & 2004 \\
\hline CLCC & Canyon Lake, CA & Putting green & Yes & 60 & 2003 \\
\hline DICC & Diablo, CA & Putting green & Yes & 32 & 2004 \\
\hline EGGC & Corona, CA & Putting green & Yes & 60 & 2003 \\
\hline FUGC & Fullerton, CA & Putting green & Yes & 60 & 2002 \\
\hline SCCC & San Jose, CA & Fairway & No & 60 & 2003 \\
\hline SHGC & San Bernardino, CA & Putting green & Yes & 40 & 2003 \\
\hline TCGC & Temecula, CA & Fairway & No & 60 & 2002 \\
\hline Total & $\ldots$ & $\ldots$ & $\ldots$ & 481 & $\ldots$ \\
\hline
\end{tabular}

${ }^{a}$ All isolates were collected from annual bluegrass (Роа аппиа) plants infected with Colletotrichum cereale.

${ }^{\mathrm{b}}$ Benzimidazole fungicides had been in use at these locations since their registration in California.
The remaining 361 isolates from the remaining eight $C$. cereale populations were tested using only the single discriminatory doses of thiophanate-methyl at 0 and 10 $\mu \mathrm{g} / \mathrm{ml}$ that appeared to clearly distinguish MBC-resistant from MBC-sensitive isolates. Assays were performed as described above, except using only these two concentrations of the fungicide.

In vivo sensitivity of isolates to $\mathrm{MBC}$ fungicides. To confirm that isolates testing as resistant in vitro were not controlled in vivo, four isolates, two from the baseline population (TCGC-5.31 and 5.35) and two from the fungicide-exposed population (AHCC-10.43 and 10.48), were used to perform in vivo greenhouse experiments. Annual bluegrass ('Trueputt'; DLF International, Halsey, OR) was seeded at the rate of $19 \mathrm{~g} / \mathrm{m}^{2}$ in University of California soil-less mix (UC Mix) in 7.5-cm-diameter plastic pots and grown for 6 weeks before inoculation. Plants were maintained at ambient greenhouse conditions (approximately 20 to $30^{\circ} \mathrm{C}$ ), clipped at a height of $5 \mathrm{~cm}$ once per week, and watered as needed. A factorial design was used, evaluating the four isolates and three treatments in each experiment. Three pots of plants were used for each fungicide-isolate combination, with the experiment being performed three times.

Pots of plants were sprayed with thiophanate-methyl or benomyl at $11 \mathrm{~g} /$ liter (equal to the field rate of $9.1 \mathrm{~kg} / \mathrm{ha}[3 \mathrm{oz}$ a.i./1,000 ft $\left.{ }^{2}\right]$ ), or $\mathrm{sdH}_{2} \mathrm{O}$ only until run off, using a $\mathrm{CO}_{2}$-powered sprayer fitted with a single TeeJet 8002 VS nozzle (R\&D Sprayers, Opelousas, LA) at a pressure of 2.0 atmospheres. Twenty-four hours later, plants were inoculated with a conidial suspension from either isolates TCGC5.31, TCGC-5.35, AHCC-10.43, or AHCC-10.48. Conidia were harvested from 14-day-old cultures grown on 1/4-PDA at $28^{\circ} \mathrm{C}$ by flooding plates with $\mathrm{sdH}_{2} \mathrm{O}$ and rubbing the surfaces with a rubber policeman. The suspensions were filtered through cheesecloth and the spore concentrations adjusted to $1 \times 10^{5}$ conidia/ml with $\mathrm{sdH}_{2} \mathrm{O}$. Each suspension was sprayed onto plants as described above. After inoculation, plants were enclosed in plastic bags for $48 \mathrm{~h}$ and incubated at $35^{\circ} \mathrm{C}, 80 \%$ relative humidity, and $12 \mathrm{~h}$ of fluorescent light in a growth chamber (GC15; Environmental Growth Chambers, Chagrin Falls, $\mathrm{OH})$. Bags then were removed and plants were maintained in the chambers for an additional 19 days, misting plants until run-off with $\mathrm{sdH}_{2} \mathrm{O}$ once a day, using a spray bottle. Disease severity was scored for each pot at this time, rating disease severity on a 0 -to- 10 scale, with 0 equal to no disease and 10 equal to $100 \%$ of the plants showing symptoms (chlorotic leaves with and without acervuli of $C$. cereale). Results from the three experiments were pooled after testing for homogeneity of variance between experiments and ana- 
lyzed using factorial analysis of variance (ANOVA) and means of each isolatetreatment combination compared using Fishers' protected least significant difference (LSD) with $\alpha=0.05$ (SAS 9.1; SAS Institute, Cary, NC).

Determination of the molecular basis for $\mathrm{MBC}$ resistance in isolates of $C$. $c e$ reale. Two $\beta$-tubulin genes, TUB1 (GenBank accession no. M34491) and TUB2 (GenBank accession no. M34492), had been characterized previously from $C$. graminicola (20). The published gene sequences were used to construct primers to amplify $\beta$-tubulin genes from 18 selected isolates (6 sensitive and 12 resistant). Previous work indicated that the majority of point mutations conferring $\mathrm{MBC}$ resistance in other fungi were associated with amino acid changes in residues 167, 198, and 200 (16); therefore, our analyses of $\beta$-tubulin genes from the $C$. cereale isolates were directed at a nucleotide region corresponding to these amino acid residues. Primers T1-1 (5'-cgagga attccetgatcgta- $\left.3^{\prime}\right)$ and T1-2 (5'-cetgcttcat ggacaccttt- $\left.3^{\prime}\right)$ were designed to amplify a 556-bp fragment of TUB1 (including a 52bp intron), corresponding to amino acid residues 157 to 315 . Likewise, primers T2-1 (5'-ctccettggtggaggtactg- $\left.3^{\prime}\right)$ and T2-2 (5'agaggcagccatcatgttct- $3^{\prime}$ ) were used to amplify a 499-bp fragment from TUB2 corresponding to amino acid residues 138 to 303 .

Genomic DNA used for polymerase chain reaction (PCR) amplification was obtained by growing isolates for 5 days in $100 \mathrm{ml}$ of potato dextrose broth (24 $\mathrm{g}$ of dry medium per liter of $\mathrm{sdH}_{2} \mathrm{O}$ ) in closed Erlenmeyer flasks on a rotary shaker set at $120 \mathrm{rpm}$ and $28^{\circ} \mathrm{C}$. Tissue was harvested by vacuum filtration through sterile filter paper (47-mm-diameter, $0.8-\mu \mathrm{m}$ pore size) using a filter funnel (Nalgene, Rochester, NY). Harvested mycelia then was scraped from the filter and ground with a mortar and pestle after freezing with liquid nitrogen. DNA was extracted from the ground mycelia using the Puregene DNA purification kit (Gentra Systems, Inc., Minneapolis, MN) following the manufacturer's instructions for plant tissue, yielding approximately $500 \mu \mathrm{g}$ of DNA per milliliter per sample.

PCR amplification was performed on DNA from each of the 18 isolates, using separate reactions for the amplification of $T U B 1$ and TUB2. PCR amplification was carried out in a $20-\mu l$ reaction volume containing $10 \mathrm{ng}$ of genomic DNA, 1× PCR buffer (200 mM Tris-HCl, pH 8.4, and $500 \mathrm{mM} \mathrm{KCl}), 0.2 \mathrm{mM}$ each dNTP, $0.3 \mu \mathrm{M}$ each of the forward and reverse primers, $2.5 \mathrm{mM} \mathrm{MgCl}$, and $0.5 \mathrm{U}$ of Taq polymerase (Invitrogen Corp., Carlsbad, CA). Amplification was performed on a PTC-200 DNA Engine (MJ Research, Waltham, MA) using an initial denaturation step of $95^{\circ} \mathrm{C}$ for $1 \mathrm{~min}$ followed by 30 cycles of $94^{\circ} \mathrm{C}$ for $1 \mathrm{~min}, 57^{\circ} \mathrm{C}$ for $1 \mathrm{~min}$, and $72^{\circ} \mathrm{C}$ for $1 \mathrm{~min}$, followed by a final extension step at $72^{\circ} \mathrm{C}$ for $1 \mathrm{~min}$. PCR products were visualized by electrophoresis using $1.5 \%$ agarose-Tris-borate-EDTA gels run at $95 \mathrm{~V}$ for $50 \mathrm{~min}$. PCR products then were cloned into an Escherichia coli vector system (pGEM-T Easy Vector System; Promega Corp; Madison, WI) following the manufacturer's instructions and sequenced at the University of California, Riverside Genomics Core Sequencing facility using Big Dye Terminator v3.1 chemistry (Applied Biosystems, Foster
City, CA). Nucleotide sequences were translated to a polypeptide using BioTools (UMass Medical School, Worchester, MA). The resulting nucleotide and amino acid sequences were compared with the published C. graminicola TUB1 and TUB2 sequences (20) and to each other using ClustalW (10) to determine differences in both nucleotide and amino acid sequences.

\section{RESULTS}

In vitro responses in a baseline and an exposed population to thiophanate-

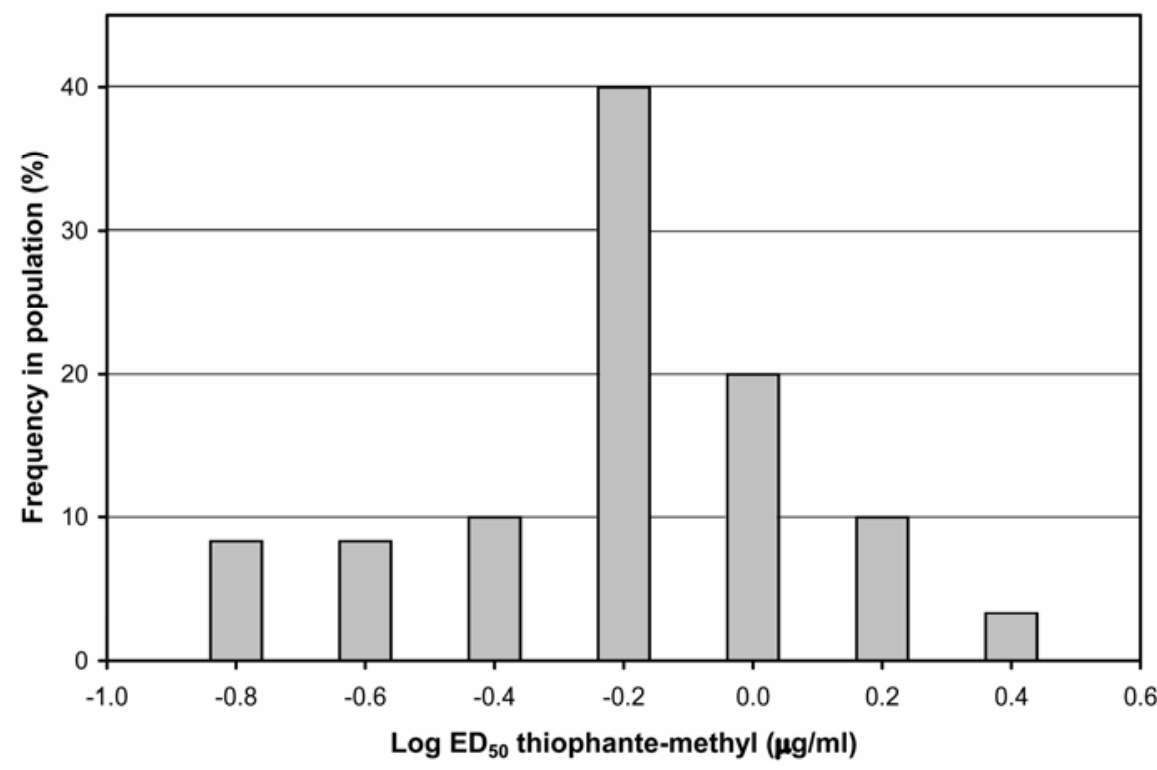

Fig. 1. Distribution of sensitivity in 60 baseline isolates of Colletotrichum cereale to thiophanatemethyl. Log $50 \%$ effective dose $\left(\log \mathrm{ED}_{50}\right)$ values were calculated from the relative growth of isolates on quarter-strength potato dextrose agar amended with the fungicide at 0 to $30 \mu \mathrm{g} / \mathrm{ml}$. X-axis labels represent the midpoint of each distribution category.

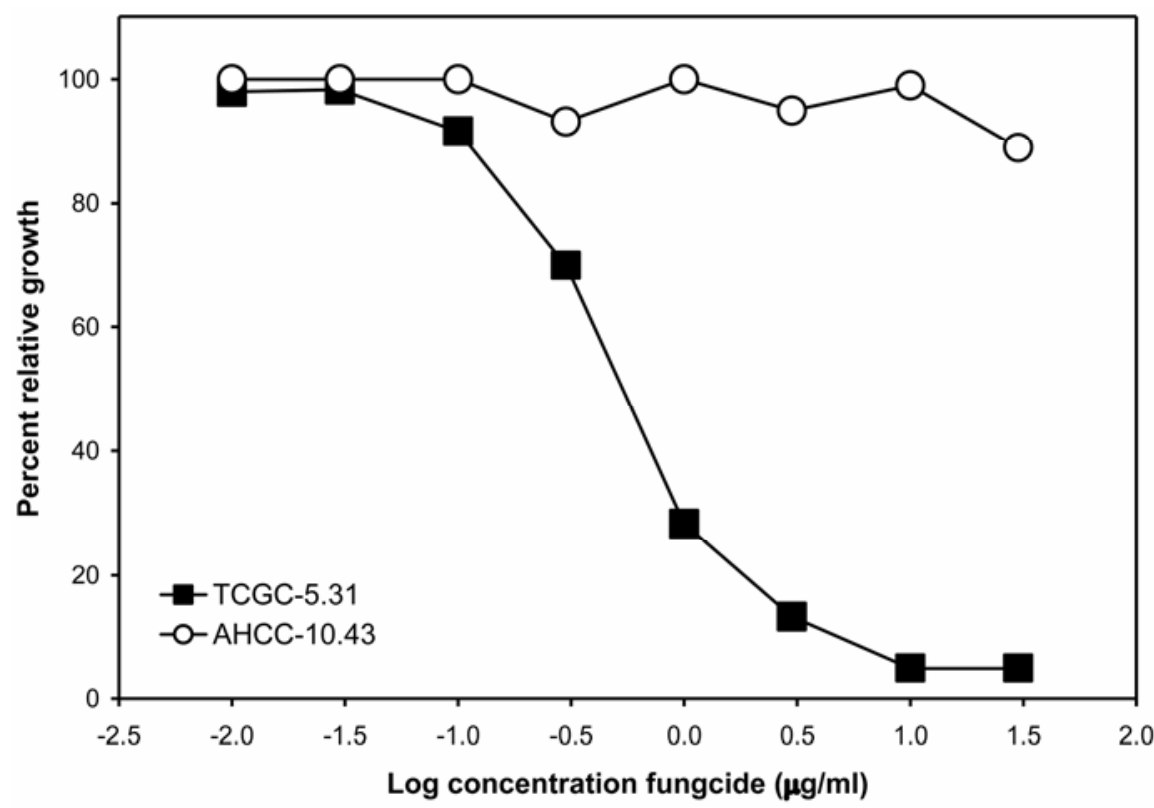

Fig. 2. Responses of Colletotrichum cereale isolates from an unexposed population (TCGC-5.31) and a fungicide-exposed population (AHCC-10.43) to increasing concentrations of thiophanate-methyl in quarter-strength potato dextrose agar. Isolates were evaluated after 7 days of growth at $28^{\circ} \mathrm{C}$. Percent relative growth is based on the colony diameter of the isolate at the tested concentration relative to the colony diameter of the isolate in the absence of the fungicide. 
methyl and benomyl. For the 60 isolates from the unexposed, baseline population TCGC, the calculated $\mathrm{ED}_{50}$ values of thiophanate-methyl ranged from 0.14 to 2.3 $\mu \mathrm{g} / \mathrm{ml}$, with a mean of $0.75 \mu \mathrm{g} / \mathrm{ml}$ (Fig. 1). $\mathrm{RG}$ values for these isolates grown on the thiophanate-methyl amended plates at 10 $\mu \mathrm{g} / \mathrm{mg}$ ranged from 0 to $29 \%$ (mean = $9.1 \%$, standard deviation $=7.1 \%$ ) . For 57 of the 60 isolates from exposed population AHCC, there was no effective dose response to the range of concentrations tested; hence, $\mathrm{ED}_{50}$ values could not be determined (Fig. 2). RG values among these 57 isolates grown with thiophanatemethyl at $10 \mu \mathrm{g} / \mathrm{mg}$ ranged from 80 to $100 \%$, with a mean of $91 \%$ (data not shown). Three isolates from population AHCC had $\mathrm{ED}_{50}$ values of $0.31,0.50$, and $0.78 \mu \mathrm{g} / \mathrm{ml}$, indicating that they were similar to those from the baseline population and still sensitive to the fungicide.

Results for the experiment using benomyl and 25 isolates from each of the baseline and exposed populations showed that isolates not responsive to thiophanatemethyl in vitro also were nonresponsive to benomyl. For the 25 isolates selected from baseline population TCGC, the $\mathrm{ED}_{50}$ values for thiophanate-methyl ranged from 0.34 to $2.3 \mu \mathrm{g} / \mathrm{ml}$ (mean $0.85 \mu \mathrm{g} / \mathrm{ml}$ ) and, for benomyl, it ranged from 0.032 to 0.52 $\mu \mathrm{g} / \mathrm{ml}$ (mean $0.15 \mu \mathrm{g} / \mathrm{ml}$ ) (Fig. 3). In contrast, $\mathrm{ED}_{50}$ values for benomyl could not be calculated for any of the isolates selected from population AHCC. For both fungicides, $\mathrm{ED}_{50}$ values for these isolates were considered to be $>30 \mu \mathrm{g} / \mathrm{ml}$, indicating cross-resistance between these two MBC fungicides (Fig. 3).

Relative sensitivity among $C$. cereale populations to thiophanate-methyl. Using RG values determined at the discriminatory dose of thiophanate-methyl at 10 $\mu \mathrm{g} / \mathrm{ml}$, most of the fungicide-exposed populations showed a high frequency of isolates insensitive to thiophanate-methyl (Fig. 4). Isolates from populations SHGC, CLGC, and EGGC had RG values clearly distinct from those of the baseline population TCGC, whereas population ANGC had 2 of 25 isolates with RG values inside the baseline range. The distribution of $R G$ values from exposed population DICC was similar to that of the baseline population TCGC, as was that of the other unexposed population SCCC.

In vivo control of isolates with $\mathrm{MBC}$ fungicides. Variance among experiments was homogenous $(P<0.05)$, allowing us to combine experiments to perform factorial ANOVA which indicated significant effects for isolate, treatment, and isolatetreatment interaction (all $P<0.001$ ). This reflects the clear differences between isolate responses to the benzimidazole fungicides. Disease severity for water-treated plants was equal for all isolates. Preventive application of either thiophanate-methyl or benomyl at $11 \mathrm{~g} /$ liter provided 89 to $90 \%$ control of baseline isolates TCGC-5.31 and 5-35 when compared with the water- only check treatment (Fig. 5). There was no difference between control of either of these isolates with thiophanate-methyl or benomyl (Fisher's protected LSD, $\alpha=$ 0.05). Conversely, both MBC fungicides provided less than $5 \%$ control of isolates AHCC-10.43 and 10-48. There was no difference between fungicides for the control of either isolate and, for both isolates, the amount of control was statistically equal to treatment with water (Fisher's protected LSD, $\alpha=0.05$ ).

Molecular basis of $\mathrm{MBC}$ resistance in isolates of $C$. cereale. For TUB1, nucleotide sequences for the amplified fragment from the $18 C$. cereale isolates tested were only 84 to $94 \%$ similar to the $C$. graminicola TUB1 sequence but were 97 to $100 \%$ similar to each other. The deduced amino acid sequence corresponding to residues 157 to 315 in the $C$. cereale isolates were 99\% similar to the sequence for TUB1 and 99 to $100 \%$ similar to each other. Examination of the region between amino acid residues 160 and 210 in MBC-sensitive and MBC-resistant isolates indicated $100 \%$ sequence identity among each other and with TUB1 (Fig. 6).

For $T U B 2$, nucleotide sequences for the amplified fragment from the $18 \mathrm{C}$. cereale isolates were 94 to $98 \%$ similar to the $C$. graminicola TUB2 sequence and 99 to $100 \%$ similar among each other. The deduced amino acid sequence corresponding to residues 138 to 297 were 99 to $100 \%$ similar to the sequence for the C. gramini-

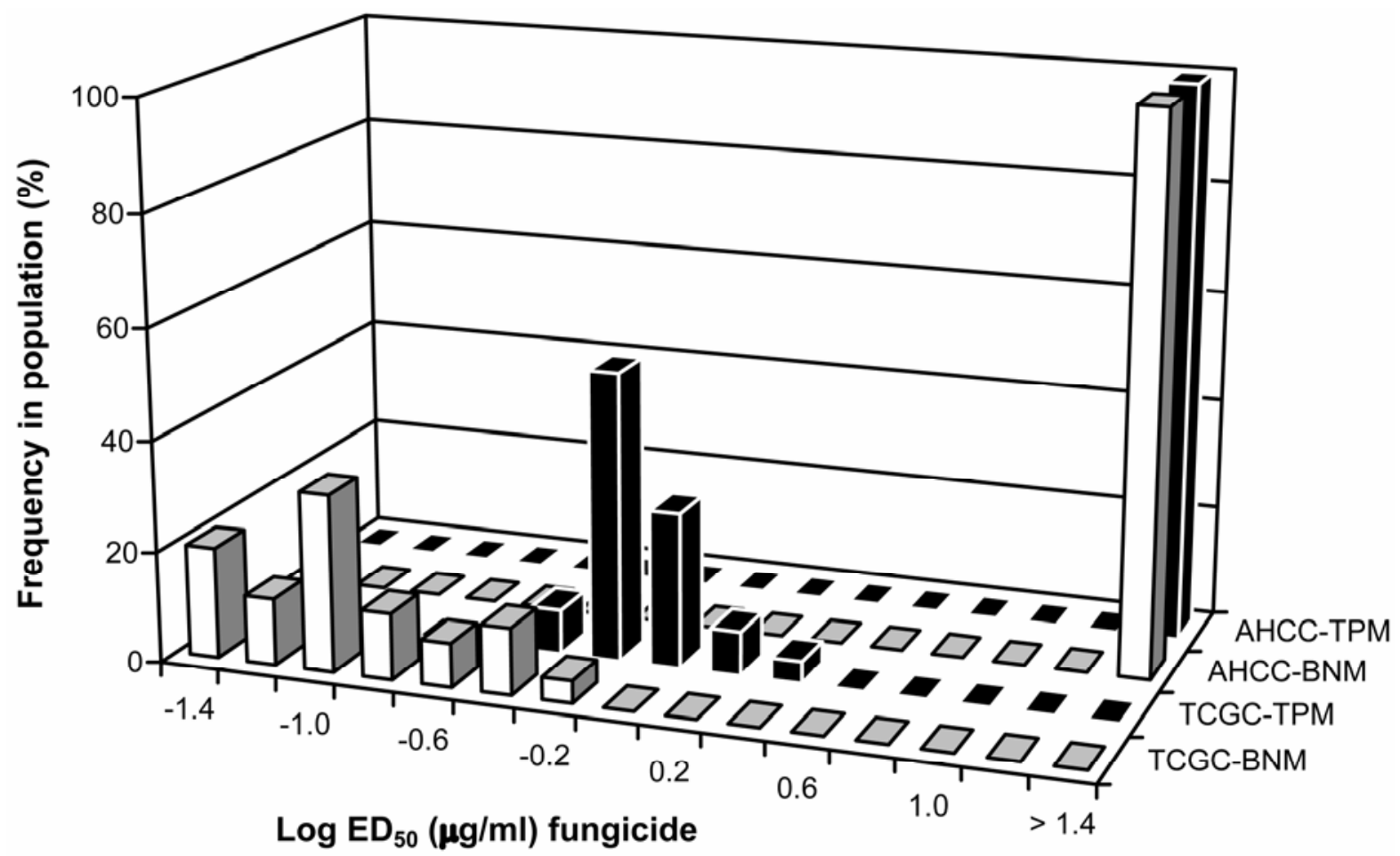

Fig. 3. Frequency distribution of sensitivity to thiophanate-methyl (TPM) and benomyl (BNM) in populations of Colletotrichum cereale from an unexposed location (TCGC) and a fungicide-exposed location (AHCC). Twenty-five isolates were tested from each population. Log 50\% percent effective dose (log $\mathrm{ED}_{50}$ ) values were calculated based on testing of isolates on quarter-strength potato dextrose agar amended with fungicide at 0 to $30 \mu \mathrm{g} / \mathrm{ml}$. For isolates from population $\mathrm{AHCC}$ that were not responsive to the range of fungicide concentrations used, $\log \mathrm{ED}_{50}$ was considered to be higher than 1.4. X-axis labels represent the midpoint of each distribution category. 
cola TUB2 and $99 \%$ similar among each other. Examination of the region between residues 160 and 210 indicated the presence of a single amino acid residue change from glutamic acid (E) to lysine $(\mathrm{K})$ at position 198 in all isolates insensitive to thiophanate-methyl in vitro. This amino acid change was encoded by a single guanine to adenosine base pair change at position 592, resulting in the codon AAG (lysine) being present instead of GAG (glutamic acid) in the sensitive $C$. cereale isolates and the TUB2 sequence from $C$. graminicola.

\section{DISCUSSION}

In this study on $C$. cereale, we present information on a methodology that can be used to monitor $\mathrm{MBC}$ resistance, the presence and distribution of MBC-resistant isolates from California golf course populations, cross resistance in these isolates to thiophanate-methyl and benomyl, and the molecular basis of MBC resistance. The presence of MBC resistance in C. cereale is a likely contributing factor to the inability of golf course superintendents to control this disease with fungicide programs.

The methodology presented here is simple and applicable for future monitoring studies. It would appear that the single discriminatory dose for thiophanate-

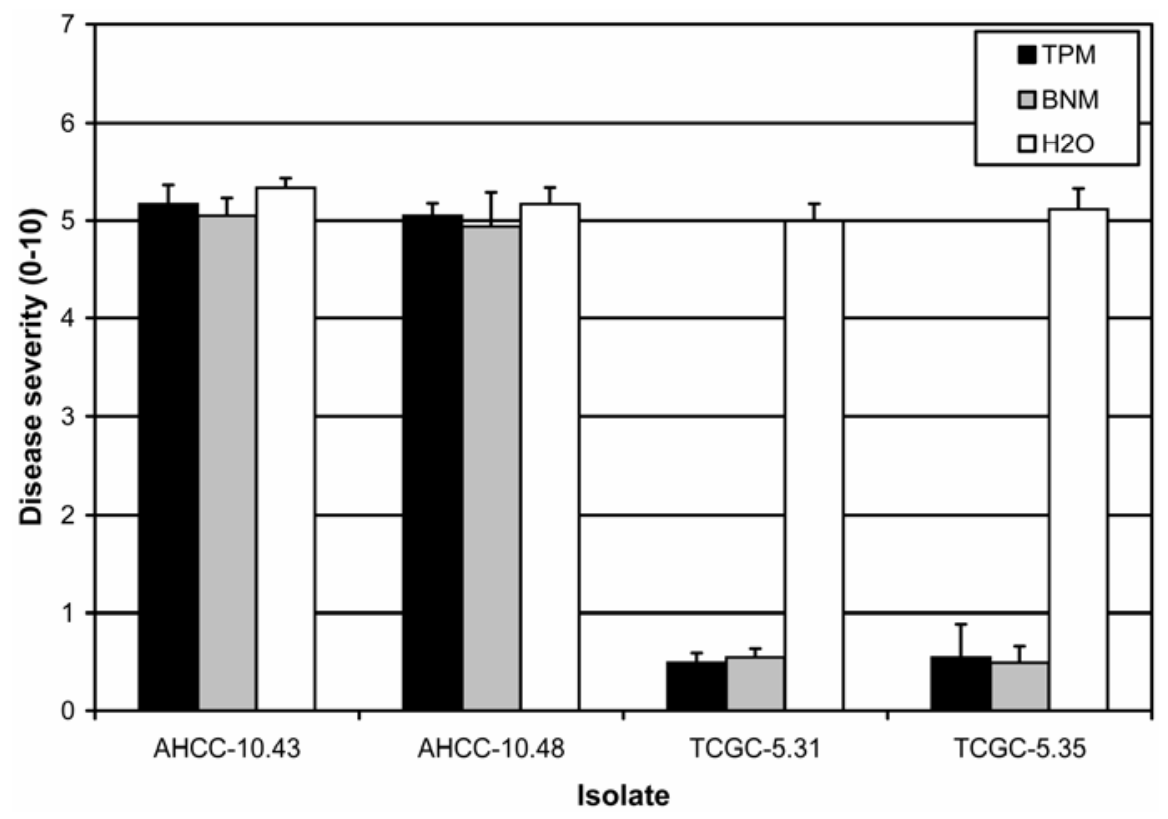

Fig. 5. Control of anthracnose caused by Colletotrichum cereale isolates sensitive (TCGC-5.31 and TCGC-5.35) and resistant (AHCC-10.43 and AHCC-10.48) to methyl benzimidazole carbamate fungicides on 6-week-old annual bluegrass plants by thiophanate-methyl (TPM), benomyl (BNM), or water $(\mathrm{H} 2 \mathrm{O})$. Relative sensitivity of the isolates were determined in vitro. Plants were sprayed with the fungicides at $11 \mathrm{mg} / \mathrm{ml}$ and inoculated $24 \mathrm{~h}$ later with a conidial suspension from each of the isolates. Disease severity was rated 21 days after inoculation, with $0=$ no disease and $10=$ all plants symptomatic. Bars represent the means of three experiments, with the error bars representing the standard deviation of the means.

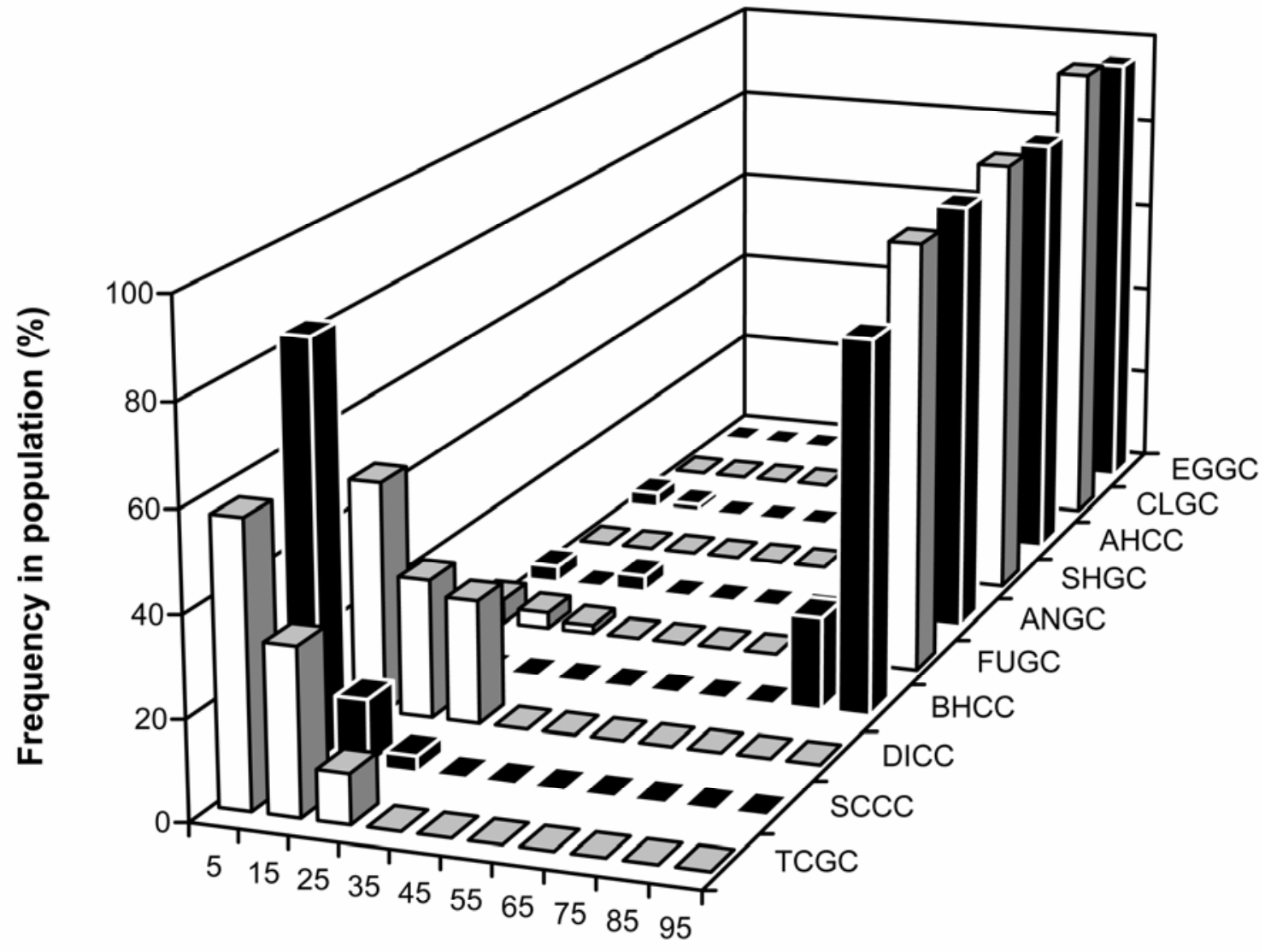

$\%$ relative growth at $10 \mu \mathrm{g} / \mathrm{ml}$ thiophanate-methyl

Fig. 4. Frequency distributions of the relative growth of 10 Colletotrichum cereale populations determined at the single discriminatory thiophanate-methyl dose of $10 \mu \mathrm{g} / \mathrm{ml}$. X-axis labels represent the midpoint of each distribution category. 
methyl of $10 \mu \mathrm{g} / \mathrm{ml}$ would be adequate to distinguish between resistant and sensitive isolates. None of the sensitive isolates grew more than $30 \%$ relative to the 0 $\mu \mathrm{g} / \mathrm{ml}$ check in $1 / 4$-PDA when tested at this dose. Furthermore, the method is predictive of sensitivity to field applications of MBC fungicides because a subset of isolates testing as $\mathrm{MBC}$ resistant in the in vitro assays also were resistant to benomyl and thiophanate-methyl in vivo.

The presence of MBC resistance in populations of $C$. cereale was not surprising given the identification of benomylresistant isolates of the pathogen in Michigan in 1989 (7); anecdotal reports of resistance from golf course superintendents; lack of disease control in University field trials from Pennsylvania (28-32), New Jersey (26), Georgia (2), California $(9,18)$, and Connecticut (13); and the long history of resistance development to MBC fungicides in numerous other pathogens since 1979 (8). The two populations that were completely sensitive, TCGC and SCCC,
(Table 1) were taken from unsprayed fairways. Historically, fungicide applications to fairways to control diseases are very rare in California due to the arid climate and general lack of humidity and rainfall conducive for summer foliar diseases. Although exact application records were not available for examination, the seven locations having populations with a high frequency of resistance ( $>90 \%$ ) had been using thiophanate-methyl or benomyl as a regular part of their fungicide programs for a number of years since the registration of these fungicides in 1971 and 1989 (California Department of Pesticide Regulation, personal communication). However, population DICC was taken from a location that had used either benomyl or thiophanatemethyl only sparingly, with no more than one application per year for the last 10 years. The difference in pathogen resistance to MBC among these sites reflects the cumulative effects of repeated singlesite mode-of-action fungicide use and risk of resistance development as predicted by
Delp (6) and eloquently discussed by Köller et al. (15). It also is interesting to note that all of the isolates used in this study from fungicide-exposed populations were QoI resistant and reduced in sensitivity to DMI fungicides as determined by earlier studies $(34,35)$. The presence of some MBC-sensitive isolates from these QoI- and DMI-resistant populations may reflect differential selection pressure by the use of different fungicide classes or, perhaps, more rapid selection for QoI and DMI resistance due to their more frequent use for other diseases of annual bluegrass that occur at the same time that $C$. cereale is active. These include summer patch (Magnaporthe poae), rapid blight (Labyrinthula terrestris) and Rhizoctonia diseases. Nonetheless, the presence of isolates in exposed locations with multiple resistance to QoIs, DMIs, and MBCs appears common.

At the locations with a high frequency of MBC-resistant $C$. cereale isolates, thiophanate-methyl use continued despite the

Isolate
AHCC-10.43
AHCC-10.48
ANCG-17.28
ANCG-17.30
CLGC-5.12
CLGC-5.13
DICC-8.62
DICC-8.65
EGGC-21
EGGC-22
FUGC-2.2
FUGC-11.4
SCCC-6.18
SCCC-6.19
SHGC-26
SHGC-28
TCGC-5.31
TCGC-5.35
TUB1

\section{Isolate}

AHCC -10.43

AHCC -10.48

ANCG-17.28

ANCG-17.30

CLGC -5.12

CLGC -5.13

DICC -8.62

DICC -8.65

EGGC-21

EGGC-22

FUGC-2.2

FUGC-11. 4

SCCC -6.18

SCCC -6.19

SHGC -26

SHGC -28

TCGC-5. 31

TCGC-5. 35

TUB2

\begin{abstract}
Status
resistant

resistant

resistant

resistant

resistant

resistant

resistant

resistant

resistant

resistant

resistant

resistant

resistant

resistant

sensitive

sensitive

sensitive

sensitive

-.-.-.-.-
\end{abstract}

\section{Status}

resistant

resistant

resistant

resistant

resistant

resistant

sensitive

sensitive

resistant

resistant

resistant

resistant

sensitive

sensitive

resistant

resistant

sensitive

sensitive

-.-.-.-.
GenBank

Accession\#

EU116292

EU116293

EU116294

EU116295

EU116296

EU116297

EU116298

EU116299

EU116300

EU116301

EU116302

EU116303

EU116304

EU116305

EU116306

EU116307

EU116308

EU116309

M34491

GenBank

Accession\#

EU116274

EU116275

EU116276

EU116277

EU116278

EU116279

EU116280

EU116281

EU116282

EU116283

EU116284

EU116285

EU116286

EU116287

EU116288

EU116289

EU116290

EU116291

M34492

\begin{tabular}{lllll} 
& 170 & 180 & 190 & 200 \\
\hline ATFSV & LPSAKVSEVV & VEPYNATLSI & HQLVENSDET & FCIDN \\
ATFSV & LPSAKVSEVV & VEPYNATLSI & HQLVENSDET & FCIDN \\
ATFSV & LPSAKVSEVV & VEPYNATLSI & HQLVENSDET & FCIDN \\
ATFSV & LPSAKVSEVV & VEPYNATLSI & HQLVENSDET & FCIDN \\
ATFSV & LPSAKVSEVV VEPYNATLI & HQLVENSDET & FCIDN \\
ATFSV & LPSAKVSEVV VEPYNATLSI & HQLVENSDET & FCIDN \\
ATFSV & LPSAKVSEVV VEPYNATLSI & HQLVENSDET & FCIDN \\
ATFSV & LPSAKVSEVV VEPYNATLSI & HQLVENSDET & FCIDN \\
ATFSV & LPSAKVSEVV VEPYNATLSI & HQLVENSDET & FCIDN \\
ATFSV & LPSAKVSEVV VEPYNATLS & HQLVENSDET & FCIDN \\
ATFSV & LPSAKVSEVV VEPYNATLSI & HQLVENSDET & FCIDN \\
ATFSV & LPSAKVSEVV VEPYNATLSI & HQLVENSDET & FCIDN \\
ATFSV & LPSAKVSEVV VEPYNATLSI & HQLVENSDET & FCIDN \\
ATFSV & LPSAKVSEVV VEPYNATLSI & HQLVENSDET & FCIDN \\
ATFSV & LPSAKVSEVV VEPYNATLSI & HQLVENSDET & FCIDN \\
ATFSV & LPSAKVSEVV VEPYNATLSI & HQLVENSDET & FCIDN \\
ATFSV & LPSAKVSEVV VEPYNATLSI & HQLVENSDET & FCIDN \\
ATFSV & LPSAKVSEVV VEPYNATLSI & HQLVENSDET & FCIDN \\
ATFSV & LPSAKVSEVV & VEPYNATLSI & HQLVENSDET & FCIDN
\end{tabular}

170

180

190

ATFSV VPSPKVSDTV VEPYNATLSV HQLVENSD

ATFSV VPSPKVSDTV VEPYNATLSV HQLVENSD

ATFSV VPSPKVSDTV VEPYNATLSV HQLVENSDK

ATFSV VPSPKVSDTV VEPYNATLSV HQLVENSDK

ATFSV VPSPKVSDTV VEPYNATLSV HQLVENSDKT FCIDN

ATFSV VPSPKVSDTV VEPYNATLSV HQLVENSDKT FCIDN

ATFSV VPSPKVSDTV VEPYNATLSV HQLVENSDET FCIDN

ATFSV VPSPKVSDTV VEPYNATLSV HQLVENSDET FCIDN

ATFSV VPSPKVSDTV VEPYNATLSV HQLVENSDKT FCIDN

ATFSV VPSPKVSDTV VEPYNATLSV HQLVENSDKT FCIDN

ATFSV VPSPKVSDTV VEPYNATLSV HQLVENSDKT FCIDN

ATFSV VPSPKVSDTV VEPYNATLSV HQLVENSDKT FCIDN

ATFSV VPSPKVSDTV VEPYNATLSV HQLVENSDET FCIDN

ATFSV VPSPKVSDTV VEPYNATLSV HQLVENSDET FCIDN

ATFSV VPSPKVSDTV VEPYNATLSV HQLVENSDKT FCIDN ATFSV VPSPKVSDTV VEPYNATLSV HQLVENSDKT FCIDN ATFSV VPSPKVSDTV VEPYNATLSV HQLVENSDET FCIDN ATFSV VPSPKVSDTV VEPYNATLSV HQLVENSDET FCIDN ATFSV VPSPKVSDTV VEPYNATLSV HQLVENSDET FCIDN

Fig. 6. Comparison of TUB1 and TUB2 amino acid sequences corresponding to residues 165 to 205 for 18 isolates of Colletotrichum cereale and the corresponding sequence from a previously described isolate of $C$. graminicola. Isolates are designated as either sensitive or resistant to methyl benzimidazole carbamate fungicides on the basis of in vitro tests. Highlighted residues show deviations from the C. graminicola TUB1 and TUB2 sequence. 
fungicide providing decreasing control of the disease because fungicide resistance in the pathogen populations was not recognized. Many of these superintendents assumed the lack of control was caused by factors other than resistance. This underlines the importance of monitoring programs and recognizing resistance issues as part of an integrated pest management strategy for disease control. The sampling method used for this study potentially could overestimate the actual proportion of MBC resistance from the putting green populations. In this case, we sampled from diseased areas that both developed after fungicide applications and tended to be concentrated on only one part of the green. A more random sampling pattern from the whole green would have been more representative of the whole green population, but it was not possible to do so for this study. Nonetheless, the results do reflect the clear presence of resistance at these locations.

This is the first characterization of MBC resistance in $C$. cereale from turfgrass populations at both a population and molecular level. With regard to other Colletotrichum spp., resistance to MBC fungicides has been described for a few species, including C. gloeosporioides $(1,17,22,23)$, C. museae (5), C. coffeanum (19), C. lindemuthianum (27), and $C$. graminicola (21). Molecular characterization of MBC resistance has been found to be conferred by a single nucleotide change in TUB2 resulting in a glutamic acid to alanine substitution at amino acid position 198 in $C$. gloeosporioides $(1,17,22)$. This is unlike the glutamic acid to lysine substitution at amino acid position 198 we have described here for C. cereale.

It is interesting to note that no amino acid substitutions in $C$. cereale TUB1 sequences were associated with the MBCresistant phenotypes. Buhr and Dickman (1) and Panaccione and Hanau (20) both had shown that TUB1 in $C$. gloeosporioides f. sp. aeschynomene and $C$. graminicola was expressed in conidiating mycelia whereas TUB2 was expressed in conidia, conidiating mycelia, and vegetative mycelia. Because $T U B 2$ appears to be the major allele expressed by these Colletotrichum spp., it would make sense that selection for mutations in TUB2 would be the major factor for resistance development to the MBC fungicides in C. cereale. $T U B 1$ does appear to play a role in conidial development; therefore, it would be interesting to determine its role in the reaction of resistant isolates to $\mathrm{MBC}$ fungicides and why no significant amino acid substitutions were found in this gene.

The practical impact of this work indicates that $\mathrm{MBC}$ resistance is present in California populations of $C$. cereale and should be considered as part of an overall anthracnose management program. The results presented here likely reflect the same situation in other geographic areas of the United States where MBC fungicide use is common for the control of the disease. For locations with a high frequency of MBC resistance, alternatives to thiophanate-methyl use should be examined whereas, for locations where the pathogen is still sensitive, thiophanate-methyl use should be closely monitored and steps taken to delay the onset of resistance to this fungicide. The presence of resistance in $C$. cereale to $\mathrm{QoI}$ and DMI fungicides $(33,35,36)$ further complicates anthracnose management, and this resistance to multiple fungicide classes underlines the need to carefully use single-site mode-of-action fungicides in spray programs and to focus on alternative management tactics for this disease in turfgrass.

\section{ACKNOWLEDGMENTS}

This work was partially funded by Syngenta Professional Products, Greensboro, NC. This work is dedicated to the memory of Sharon L. Midland. We thank J. C. Rios for her contributions to this work and the golf course superintendents associations of California for their support.

\section{LITERATURE CITED}

1. Buhr, T. L., and Dickman, M. B. 1994. Isolation, characterization and expression of a second beta-tubulin-encoding gene from Colletotrichum gloeosporioides f. sp. aeschynomene. Appl. Environ. Microbiol. 60:4155-4159.

2. Burpee, L. L., Stephens, S. L., and MartinezEspinoza, A. D. 2004. Control of anthracnose caused by a benzimidazole- and QoI-resistant isolate of Colletotrichum graminicola, 2003. Fungic. Nematicide Tests 59:T016.

3. Cole H., Warren, C. G., and Sanders, P. L. 1974. Fungicide tolerance-a rapidly emerging problem in turfgrass disease control. Proc. Int. Turf. Res. Conf. 2:344-349.

4. Crouch, J. A., Clarke, B. B., and Hillman, B. I. 2006. Unraveling evolutionary relationships among the divergent lineages of Colletotrichum causing anthracnose disease in turfgrass and corn. Phytopathology 96:46-60.

5. de Lapeyre de Bellaire, L., and Dubois, C. 1997. Distribution of thiabendazole-resistant Colletotrichum musae isolates from Guadeloupe banana plantations. Plant Dis. 81:1378-1383.

6. Delp, C. J. 1980. Coping with resistance to disease control agents. Plant Dis. 64:654-657

7. Detweiler, A. R., Vargas, J. M., Jr., and Brendt, W. L. 1989. Resistance of Colletotrichum graminicola to benomyl. Proc. Int. Turf. Res. Conf. 6:359-362.

8. Fungicide Resistance Action Committee. 2006. FRAC List of Plant Pathogenic Organisms Resistant to Disease. Crop Life, Brussels.

9. Green, D. E. 2004. Evaluation of foliar fungicides for crown and basal rot anthracnose control in annual bluegrass, 2003. Fungic. Nematicide Tests 59:T047.

10. Higgins D., Thompson J., Gibson, T., Thompson J. D., Higgins D. G., and Gibson T. J. 1994. CLUSTAL W: improving the sensitivity of progressive multiple sequence alignment through sequence weighting, position-specific gap penalties and weight matrix choice. $\mathrm{Nu}-$ cleic Acids Res. 22:4673-4680.

11. Huth, G., and Schlosser, E. 1980. Tolerance of Fusarium nivale to benzimidazole fungicides in golf greens. Z. Veg. 4:161-164.

12. Jackson, N., and Herting, V.J. 1985. Colletotrichum graminicola as an incitant of anthracnose/basal stem rotting of cool season turfgrasses. Proc. Int. Turf. Res. Conf. 5:647-
656.

13. Kaminski, J. E., and Keneally, M. G. 2007. Preventive control of anthracnose basal rot on an annual bluegrass putting green, 2006. Plant Dis. Manage. Rep. 1:T012.

14. Köller, W. 1999. Chemical approaches to managing plant pathogens. Pages 337-376 in: Handbook of Pest Management. J. R. Ruberson, ed., Marcel Dekker, New York.

15. Köller, W., Wilcox, W. F., and Jones, A. L. 1999. Quantification, persistence, and status of dodine resistance in New York and Michigan orchard populations of Venturia inaequalis. Plant Dis. 83:66-70.

16. Ma, Z., and Michailides, T. J. 2005. Advances in understanding molecular mechanisms of fungicide resistance and molecular detection of resistant genotypes in phytopathogenic fungi. Crop Prot. 24:853-863.

17. Maymon, M., Zveibil, A., Pivonia, S., Minz, D., and Freeman, S. 2006. Identification and characterization of benomyl-resistant and sensitive populations of Colletotrichum gloeosporioides from statice (Limonium spp.). Phytopathology 96:542-548.

18. McCullough, M. D., and Wong, F. P. 2005. Evaluation of mid-season fungicide applications for the control of anthracnose on a mixed annual bluegrass and creeping bentgrass green in northern California, summer 2004. Fungic. Nematicide Tests 60:T056.

19. Okioga, D. M. 1976. Occurrence of strains of Colletotrichum coffeanum resistant to methylbenzimidazol-2-yl carbamate carbendazim and chemically similar compounds. Ann. Appl. Biol. 84:21-30.

20. Panaccione, D. G., and Hanau, R. M. 1990. Characterization of two divergent beta-tubulin genes from Colletotrichum graminicola. Gene 86:163-170.

21. Panaccione, D. G., McKiernan, M., and Hanau, R. M. 1988. Colletotrichum graminicola transformed with homologous and heterologous benomyl-resistance genes retains expected pathogenicity to corn. Mol. PlantMicrobe Interact. 1:113-120.

22. Peres, N. A. R., Souza, N. L., Peever, T. L., and L. W. Timmer. 2004. Benomyl sensitivity of isolates of Colletotrichum acutatum and $C$. gloeosporioides from citrus. Plant Dis. 88:125130.

23. Sanders, G. M., Korsten, L., and Wehner, F. C. 2000. Survey of fungicide sensitivity in Colletotrichum gloeosporioides from different avocado and mango production areas in South Africa. Eur. J. Plant Pathol. 106:745-752.

24. Schroeder, W. T., and Provvidenti, R. 1969. Resistance to benomyl in powdery mildew of cucurbits. Plant Dis. Rep. 53:271-275.

25. Smith, J. D. 1954. A disease of Poa annua. J. Sports Turf Res. Inst. 8:344-353.

26. Towers, G., Green, K., Weibel, E., Majumdar, P., and Clarke, B. B. 2003. Evaluation of fungicides for the control of anthracnose basal rot on annual bluegrass, 2002. Fungic. Nematicide Tests 58:T017.

27. Tu, J. C., and McNaughton, M. E. 1980. Isolation and characterization of benomyl resistant biotypes of the delta race of Colletotrichum lindemuthianum. Can. J. Plant Sci. 60:585590.

28. Uddin, W., Soika, M. D., Shelton, J., and Soika, E. L. 2001. Evaluation of fungicides for the control of Anthracnose on annual bluegrass and creeping bentgrass, 2000. Fungic. Nematicide Tests 56:T17.

29. Uddin, W., Soika, M. D., Shelton, J., and Soika, E. L. 2003. Effects of fungicides for control of anthracnose on a putting green, 2002. Fungic. Nematicide Tests 58:T050.

30. Uddin, W., Soika, M. D., and Soika, E. L. 2002. Evaluation of fungicides for control of anthracnose on a putting green, 2001. Fungic. Nematicide Tests 57:T03. 
31. Uddin, W., Soika, M. D., Soika, E. L., and Francl, A. 2004.Management of Anthracnose basal rot on a putting green, 2003. Fungic. Nematicide Tests 59:T031.

32. Uddin, W., Soika, M. D., Soika, E. L., and Francl, A. 2005. Management of anthracnose basal rot on a putting green with use of fungicides, 2004. Fungic. Nematicide Tests 60:T046.

33. Wong, F. P. 2003. Baseline sensitivity distribu- tion of Colletotrichum graminicola (turfgrass anthracnose) to thiophanate-methyl and detection of resistance in California populations. (Abstr.) Phytopathology 93:S91.

34. Wong, F. P., and Midland, S. L. 2007. Sensitivity distributions of California populations of Colletotrichum cereale to four sterol demethylation inhibitor fungicides: propiconazole, myclobutanil, tebuconazole and triadimefon. Plant Dis. 91:1536-1546.
35. Wong, F. P., Midland, S. L., and de la Cerda, K. A. 2007. Occurrence and distribution of QoI-resistant isolates of Colletotrichum cereale from annual bluegrass in California. Plant Dis. 91:1547-1555.

36. Wong, F. P., and Wilcox, W. F. 2002. Sensitivity to azoxystrobin among isolates of Uncinula necator: Baseline distribution and relationship to myclobutanil sensitivity. Plant Dis. 86:394 404. 